\title{
Plant responses to extended photosynthetically active radiation (EPAR)
}

\begin{abstract}
Current and future life sciences demand more data for experiments, modeling and computing. After introducing Photosynthetically Active Radiation (PAR), the quality of light was sacrificed for the quantity. PAR has an intrinsic drawback that stems from reporting light sources by a number of the irradiated quanta. In pieces of research on photosynthesis, PAR generally and appropriately is used, whereas PAR has been inappropriately used in pieces of research not dealing with photosynthesis directly as a parameter. Different light sources have diverse spectral photon fluxes (SPF), both in and out of PAR region, which can affect the results of a research quite apart from measured light intensity in PAR. Here, many published papers about light quality effects on plant growth and development are reviewed. In addition, PAR disadvantages and SPF-based extended PAR (EPAR) advantages are discussed to show that a quantitative unit cannot be sufficiently informative where photosynthesis is not the sole parameter. Instead, EPAR is proposed to be considered for research on plants and reporting the results to provide more and detailed information.
\end{abstract}

Keywords: photosynthetically active radiation (PAR), spectral photon fluxes (SPF), photosynthesis, light, plant
Volume 7 Issue 3 - 2017

\author{
Arman Pazuki, ${ }^{1,2}$ Fatemeh Aflaki, ${ }^{1,2}$ \\ Mohammad Pessarakli, ${ }^{3}$ Ekrem Gurel,' \\ Songul Gurel ${ }^{2}$ \\ 'Department of Biology, Faculty of Arts and Sciences, Abant \\ Izzet Baysal University, Turkey \\ ${ }^{2}$ Department of Plant Breeding, Sugar Research Institute, Turkey \\ ${ }^{3}$ School of Plant Sciences, College of Agriculture and Life \\ Sciences, The University of Arizona, USA
}
Correspondence: Mohammad Pessarakli, Research Professor, School of Plant Sciences, College of Agriculture and Life Sciences, The University of Arizona, Tucson, Arizona, USA, Tel (520)321-7786,Email pessarak@email.arizona.edu

Received: March 25, 2017| Published: August 04, 2017
Abbreviations: PAR, photosynthetically active radiation; EPAR, extended photosynthetically active radiation; FR, far red; IR, infra red; R, red light; SPF, spectral photon flux; B, blue light; Chl, chloroplast; Cyt, cytochrome; PSII, photosystem II; LED, light emitting diode

\section{Introduction}

Evaluatin techniques and units in various fields, including plant sciences are updated to better represent and define applied methods and materials. Since more precise techniques of measurement are emerging with the advancement of science, the current techniques and units should be replaced with new and comprehensive ones. In plant sciences, irradiance has been rarely reported in lux, and after 1981, ${ }^{1}$ predominantly in Photosynthetically Active Radiation (PAR)

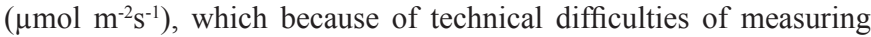
light (for instance in the near-UV region), it was trimmed off between $400-700 \mathrm{~nm},{ }^{2}$ consequently oversimplified. PAR measurement is significantly inferior to most other physical measurements in accuracy. ${ }^{1}$ However, despite short comings; PAR has not been updated after tens of years. The amount of PAR for a light source is equal to the sum of respective wavelengths photon flux, so that it is a quantitative unit devoid of the irradiance quality. Here, a number of published papers will be reviewed to highlight the importance of considering light quality both in and out of PAR region, ignored by PAR definition, to express an opinion of Extended PAR (EPAR).

\section{EPAR vs PAR and Lux}

Light sources have various Spectral Photon Fluxes (SPFs) which may extend from ultra violet (UV) ${ }^{3}$ to infra red (IR $)^{4}$ even may include a broader range of electromagnetic spectrum. ${ }^{5}$ Despite SPF added advantages over lux and PAR, SPF has almost never been employed in research on plants. In the human eyes or for plants by using lux or PAR, respectively, two very narrow bands of distinct spectrum with the same quanta may produce dissimilar luminance or photochemical reactions. In other words, it is possible to have light sources with different SPFs, while their luminance in lux or PAR in $\mu \mathrm{mol} \mathrm{m}^{-2} \mathrm{~s}^{-1}$ is the same. These units are useful, however, only in comparison of light sources with similar spectral distribution within the visible or PAR regions. ${ }^{6}$ Therefore, it is suggested that "an integrative research approach under realistic conditions is essential for future projections of the response of ecosystems". ${ }^{7}$ In plant sciences, PAR is universally accepted as a light measurement standard. Nevertheless, PAR does not cover radiation in UV, FR, and IR regions. In addition, as has been discussed earlier, the amount of light in PAR equals to all the spectrum quanta in sum, irrespective of the light intensity in each spectrum in the PAR region, let alone out of the PAR region. Therefore, redefining PAR as an extended PAR to include nearly all physiologically active radiation, up to now consigned to oblivion, is suggested.

\section{Lux: still welcomed}

Lux includes solely the visible region of electromagnetic radiation, and is tuned to the human eye, but not to plants. Moreover, lux is an integrated spectral irradiance weighted by a special weighting function which has its maximum at $555 \mathrm{~nm}$, while for all the other wavelengths is less. ${ }^{8}$ Therefore, it is not recommended in plant sciences. ${ }^{9}$ Despite the shortcomings, lux has still being measured occasionally in plant sciences. ${ }^{10-19}$

\section{Light quality, complicated by different light sources}

Light quality has an equal value to plant growth as compared to light quantity in physiology and morphology. In published papers, light treatment is normally mentioned in $\mu \mathrm{mol} \mathrm{m} \mathrm{m}^{-2} \mathrm{~s}^{-1}$. Further clarifications are usually the type of light source, (white) fluorescent tubes, incandescent lamps, etc., ${ }^{20-24}$ which all are just brands or common names with little scientific value. In addition, mentioning 
the type of light source is complicated by different light sources from various manufacturers. For instance, three fluorescent lamps, made by three companies, under the same common name show dissimilar SPFs. ${ }^{25-27}$

\section{Light sources also have radiation out of PAR region}

PAR excludes half of solar radiant energy: UV-B, UV-A, far-red (FR), and infrared (IR). Likewise, most artificial light sources have radiation in one of the UV, FR, or IR regions, even two or three of them. For example, the radiation of metal-halide, incandescent, fluorescent, and xenon lights are rich in UV, FR and IR, UV and FR, UV to IR, respectively, besides their radiation in PAR. ${ }^{28-33}$ As a case example, UV-A and FR are radiated from almost all fluorescent lamps made by Sylvania, one of the most favorite fluorescent lamp producers of researchers. ${ }^{26}$ Thus, exposed plants to radiations out of PAR region will respond to these spectra genetically, ${ }^{34}$ physiologically, and morphologically, ${ }^{35}$ which may change photosynthetic and nonphotosynthetic events effectively. In some investigations into plants, it has been tried to avoid the spectra out of PAR region by using a proper light source radiating within PAR, ${ }^{36,37}$ or using filters to prevent plants from UV, FR, or IR spectra. ${ }^{38-40}$ In most reports neither of these two techniques have been employed nor have been mentioned if used, this is in spite of the fact that data taken under artificial light sources are potentially the most erroneous ones. ${ }^{1}$

\section{Importance of light source spectra composi- tion}

"PAR should not be treated as a universal measure of the radiation available for growth". ${ }^{1}$ The importance of light quality in plant growth has been previously reviewed. ${ }^{41,42}$ PAR is generally monopolized for research focused on photosynthesis; ${ }^{1}$ however it is still used and reported for research other than photosynthesis, where it has the potential to affect photosynthesis indirectly, along with its direct effects. The composition of a light source spectra, in or out of PAR, has comprehensive effects on plants growth and development, and may induce a specific or distinct response. For instance, PAR is reported in papers investigating flowering, ${ }^{39}$ vernalization, ${ }^{43}$ stress tolerance, ${ }^{44}$ morphogenesis, secondary metabolites, ${ }^{45}$ development, ${ }^{46}$ etc. Thus, measuring light in PAR simply disregards the effect of a certain important band of electromagnetic radiation and each spectrum roles in plant responses. By considering PAR, there is no idea about red light (R) to IR ratio, or SPF in UV, or blue light (B) radiation, unless they are explicitly provided. However, the significance of $\mathrm{R} / \mathrm{IR},{ }^{47}$ $\mathrm{UV}^{48}$ and $\mathrm{B}^{49}$ band regions ${ }^{49}$ to plant growth have been reported. A specimen irradiated with a defined intensity of light, without making its quality clear, is not easy to be repeated in another laboratory with a very similar result. Therefore, providing as much information as possible about the light source in published papers is strongly suggested. ${ }^{2}$ Spectroradiometer is an advisable apparatus to define radiant energy reaching plants. To exemplify light quality importance, the following is a summary that highlights some light spectra effects on plants photosynthesis, growth, and development.

\section{Light effects at the same amount of PAR on plants}

Same amount of PAR irradiation from various light sources, particularly the artificial ones, can change the same plant response. There are many pieces of research investigated the importance of light quality effects on plants. An example is a report on soybean and sorghum growth and development grown under equal PARs from broad spectrum daylight fluorescent or blue-deficient narrow-band $(589 \mathrm{~nm})$ low pressure sodium lamps. Both lamps had similar, low, near IR and long wave IR integrals, and the same PAR $\left(500 \mu \mathrm{mol} \mathrm{m}^{-2} \mathrm{~s}\right.$ $\left.{ }^{1}\right)$. However, SPFs within 400-500, 500-600, and 600-700 nm were, respectively, 140,250 , and $109 \mu \mathrm{mol} \mathrm{m}^{-2} \mathrm{~s}^{-1}$ for the daylight fluorescent and 1,500 , and $3 \mu \mathrm{mol} \mathrm{m}^{-2} \mathrm{~s}^{-1}$ for low pressure sodium lamps. Although both had the same PAR, the plants were different in height, growth, photosynthesis, and leaf parameters. ${ }^{36}$ Based on another investigation ${ }^{38}$ into spinach under the same PARs $\left(100\right.$ and $\left.500 \mu \mathrm{mol} \mathrm{m}^{-2} \mathrm{~s}^{-1}\right), \mathrm{CO}_{2}$ assimilation rates, quantum efficiency of photosystem II (PSII), leaf nitrogen, Cytf and chloroplast (Chl) contents per unit leaf area were smaller under B deficient conditions.

Photosynthesis rate of spinach plants grown under $\mathrm{B}+\mathrm{R}$ lights at a total PAR of $300 \mu \mathrm{mol} \mathrm{m} \mathrm{m}^{-2} \mathrm{~s}^{-1}$, with B SPF of $0,30,100$, and $150 \mu \mathrm{mol} \mathrm{m} \mathrm{s}^{-1}$, was boosted with increasing B up to $100 \mu \mathrm{mol} \mathrm{m}^{-2} \mathrm{~s}^{-1} \cdot{ }^{38}$ Radiating three light sources (white, both $\mathrm{R}$ and $\mathrm{B}$ together by lightemitting diodes (LEDs), and high pressure sodium lamps) did not change photosynthesis rates in Petunia and Pelargonium, but biomass increased in both plants by R+B-LEDs; however for Chrysanthemum, in another experiment, photosynthesis rate was higher for R+B-LEDs, and contrary to previously mentioned plants, high pressure sodium lamp produced the highest biomass. ${ }^{50}$ According to Wang et al ${ }^{49}$ PAR by its quality, for example by using different light sources (white, $\mathrm{R}$, and $\mathrm{B}$ lights, each of them at $50 \pm 5 \mu \mathrm{mol} \mathrm{m}^{-2} \mathrm{~s}^{-1}$ ), is able to change leaf area, shoot length, leaf thickness, and Chl content of Cucumis sativus; hence, it can affect total photosynthesis. Here, only some of the publications have been reviewed, while there are obviously much more to mention.

\section{Blue light effects on carbon assimilation}

In contrast to $\mathrm{R}$ and FR lights, B supports more photosynthetic capacity, Chl content, and enhances leaf area ${ }^{51}$ It is suggested that Rubisco is highly-positively correlated with photosynthesis. ${ }^{52}$ Reduction of Rubisco content by introducing an antisense RNA decreased photosynthesis in transgenic tobacco plants..$^{53}$ Likewise, in low light-grown pea seedlings (acclimated to either 20 or $200 \mu \mathrm{mol}$ $\mathrm{m}^{-2} \mathrm{~s}^{-2}$ of white, B-enriched, or broad-band R), Rubisco level and per unit cell were doubled by an increase in $\mathrm{B} .{ }^{54}$ Therefore, when B proportion in a given PAR increases, a rise in Rubisco level and consequently photosynthesis is likely. Ohashi-Kaneko et al. ${ }^{22}$ reported that ${ }^{22} \mathrm{~B}+\mathrm{R}$ compared with $\mathrm{R}$ alone in rice at the same overall PAR increased its net assimilation rate, biomass production, Rubisco, and chl content. Since Rubisco is the most important target to be manipulated for boosting crop photosynthesis ${ }^{55}$ being oblivious ${ }^{55}$ to the knock-on effect of light quality on photosynthesis does not seem sensible.

\section{The effect of UV on plant growth}

Although UV-B and UV-A radiations are present in sunlight at ground level, PAR does not include UV, whereby the full complexity of UV effects on plants, both photosynthetic and non-photosynthetic, has not been revealed yet. ${ }^{35}$ Stratospheric ozone depletion has resulted in increasing levels of UV-B radiation reaching plants. ${ }^{56}$ UV-B radiation effects on field crops are mainly deleterious, ${ }^{57}$ but still relatively small. ${ }^{58}$ Notwithstanding the well-known negative effects of UV on life, at a low incidence, it may be even beneficial. For example, increased level of UV-B resulted in a small increase in 
yield and a noticeable increase in harvest index of bean (Phaseolus vulgaris L.). ${ }^{59}$ Likewise, in wheat (Triticum durum) and broad beans (Vicia faba) exposed to high levels of UV-B, the plants height, tiller numbers, dry mass and leaf area were positively correlated with UV-B exposure during the vegetative growth stages, meanwhile for wheat, the grain mass and number of spikes increased significantly. ${ }^{60}$ The red alga (Gracilaria lemaneiformis) can transfer UV-A energy efficiently, in the same way as that of PAR, to drive photosynthesis. ${ }^{61}$

Radiating UV-A or UV-A+UV-B supplemented to ambient UV (to simulate increased UV dose after ozone layer depletion in the futur ${ }^{56}$ ) on seedlings of Laurus nobilis compared with the ambient UV (as a reference) increased leaf thickness, and biomass of root, stem, and total; but for growth parameters per area of leaf, and some water and photosynthetic indices, the treatments were insignificant. ${ }^{62}$ Solar UV-A radiation increased photosynthetic rate in situ by $12 \%$. In addition, nearly half of 55 subalpine species have a potential for photosynthetic gain under UV radiation, therefore dismissing UV-A from PAR definition may underestimate and miscalculate $\mathrm{CO}_{2}$ assimilation and $\mathrm{O}_{2}$ evolution in these regions. ${ }^{48}$ Plant photosynthetic tissues may take the advantage of solar UV to accordingly reorient with incoming light ${ }^{63}$ or to change the root: shoot ratio. ${ }^{35}$ It appears that our understanding of UV and other spectra effects, out of PAR region, on plants is not explicit, ${ }^{35,58}$ which suggests that integrating these bands in conventional PAR may help to bring eventually an end to the uncertainties in global, regional, and even in vitro scales.

\section{Light quality effects on plant pigments}

Light at different wavelengths has distinct effects on plants pigments, which itself can alter photo synthesis and light utilization efficiency in plants positively or negatively. Recently, LED technology, by having many inherit merits, has gained broad and growing acceptance in the field of lighting and has attracted much attention in indoor plant cultivation. ${ }^{64}$ Any bands of light may have a distinct effect on plant physiology both when applied alone or in combination with others. As an effect on photosynthetic pigments of plants, i.e. chl $a$ and $b, \mathrm{R}$, Green (G) and B LEDs in different combinations illuminated potato grown in vitro produced more pigments than fluorescent lamps. In addition, in the double combination of RB, R LEDs at $660 \mathrm{~nm}$ is superior to $\mathrm{R}$ at $630 \mathrm{~nm}$ in increasing the pigments. $\mathrm{Chl} a$ and $b$ have their absorption maxima at $\mathrm{R}$ and $\mathrm{B}$ wavelengths, so that it is little wonder there is general interest in having $\mathrm{R}+\mathrm{B}$ LEDs in indoor applications of study on plant. Interestingly, supplementing a G LED to the RB, a triple combination, lead to more chl $a$ and $b$, in the presence of either types of $\mathrm{R}$. The same results can be expected for soluble sugar and protein, starch, and some morphological traits. ${ }^{65}$ Plants exposed to UV accumulate flavonoids. ${ }^{66}$

Supplementing UV-A, B, G, R, and FR at 18, 130, 130, 130, and $160 \mu \mathrm{mol} \mathrm{m}^{-2} \mathrm{~s}^{-1}$ to PAR of $300 \mu \mathrm{mol} \mathrm{m}^{-2} \mathrm{~s}^{-1}$ in baby leaf lettuce increased anthocyanins concentration by $11 \%$ and $31 \%$ with supplemental UV-A and $\mathrm{B}$, respectively, carotenoids by $12 \%$ with $\mathrm{B}$, and phenolics by $6 \%$ with R, while supplemental FR decreases anthocyanins, carotenoids and chlorophyll concentrations by $40 \%, 11 \%$, and $14 \%$, respectively, compared with those under white light control. ${ }^{67}$ Radiating $200 \mu \mathrm{mol}$ $\mathrm{m}^{-2} \mathrm{~s}^{-1}$ of sole R $(640 \mathrm{~nm})$, or R+B $(455 \mathrm{~nm})\left(147.5+25.5 \mu \mathrm{mol} \mathrm{m}{ }^{-2} \mathrm{~s}\right.$ ${ }^{1}$, respectively) produced different amounts of $\mathrm{Chl} \mathrm{a,b}$ and $\mathrm{a} / \mathrm{b} \cdot{ }^{68}$ The morphological and biological effects of supplemental UV at different bands vary among plant species. For example, while UVs + PAR at high irradiance levels increased red pak choi (Brassica rapa var. chinensis, Rubi) leaf area, conversely, for Micro greens of basil
(Ocimum basilicum L., Sweet Genovese) and beet (Beta vulgaris L., Bulls Blood) it seems more stressful by decreasing leaf area. ${ }^{69}$ Protective action of phenolic compounds, e.g. anthocyanins, can result in optical masking of chlorophyll, hence decreasing photosynthetic capacity of plants. ${ }^{70}$ Contrary to negative effect of pigments of cell sap on photosynthesis, pigments of plastids, i.e. carotenoids (accessory pigments), transfer the absorbed light energy between $400-500 \mathrm{~nm}$ to Chls. ${ }^{71}$ Therefore, having plants with lower amount of nonphotosynthetic pigments may boost their productivity. ${ }^{72}$

\section{Light quality affects even callus growth and morphogenesis}

In addition to the discussed effects of light quality on whole plant, radiation out of PAR region, i.e. UV, influences plant morphogenesis, ${ }^{35}$ and interestingly callus growth and morphogenesis. In the investigations into plant callus growth, light treatment has been reported based on $\operatorname{lux}^{73-75}$ or PAR, ${ }^{76-78}$ even though the light sources might had radiated out of PAR region, e.g. UV or IR regions, that could alter callus growth and morphogenesis. ${ }^{28} \mathrm{UV}$ radiation at $371 \mathrm{~nm}$ and B-light at $419 \mathrm{~nm}$ could stimulate or inhibit callus growth and shoot initiation of tobacco callus, depending on the light intensities. However, R or FR at 590,660, and 750nm did not have any effects on callus growth or shoot initiation even at high irradiance levels. ${ }^{28}$ In equal PAR, therefore, light sources with higher radiation in B region should not have the same effects as those with lower proportion of B-light on tobacco callus growth or shoot initiation. On the other hand, if a tobacco callus does not respond to a given light intensity, it may not be responsive to increased PAR by adding to the intensity of $\mathrm{R}$ region of light as an example. Radiating 16 different light qualities at a similar light intensity by LED on Panax vietnamensis calli and plantlets produced various amount of callus fresh and dry weights, varied numbers of plantlet regeneration, and dissimilar leaf areas. ${ }^{45}$ Some unexpected effects of light on callus growth have been ascribed to indirect effects of light quality, for instance UV radiation and B-light could degrade auxin hormone and components supplemented to in vitro culture media. ${ }^{79}$ This can change plants morphology and development, and indirectly photosynthesis.

\section{Chlorophyll $\mathbf{d}$ and f: the new photo pigments}

Competition for light to drive photosynthesis has a vital role in growth of plants living in crowded communities.$^{80}$ In the evolution of photosynthesis, having new photosynthetic pigments has been pivotal to survive in a diverse range of environments to avoid rivals. ${ }^{81}$ Plant leaves are rich in chl $a$ and $b$, which strongly absorb $\mathrm{B}, \mathrm{R}$, and $\mathrm{G}$ lights to a lesser extent, but they are relatively inefficient in absorbing FR radiation $(700-800 \mathrm{~nm})$. This means that, plants under a dense canopy of leaves are not deprived of FR radiation, which slightly contributes to photosynthesis in photosystems (PSI and PSII) of plants. ${ }^{82,83}$ Recently, FR limit of PS-I has been extended up to $840 \mathrm{~nm},{ }^{84}$ or at most $850 \mathrm{~nm} .{ }^{85}$ However, it was reported for the first time that a unique cyanobacterium, Acaryochloris marina, could efficiently use the radiation of longer wavelengths for photosynthesis in PSI and PSII by means of Chl $d .^{86-89}$ The energy of the light absorbed by Chl $d$ is lower than $\mathrm{Chl} a$, and yet oxygenic photosynthesis is operative. ${ }^{88}$ Surprisingly, researchers' attempt to isolate new $\mathrm{Chl} d$-containing prototroph revealed an even more red-shifted pigment named $\mathrm{Chl} f$ .${ }^{90}$ Brief fame of $A$. marina as the only characterized organism that uses chl $d$ as a major photo pigment ${ }^{91}$ came to an end when more cyan bacteria utilizing $\mathrm{Chl} d$ and $f$ have been identified. ${ }^{92-94}$ PAR is 
suggested to be extended more broadly to mean any radiation directly used in photosynthesis by photosynthetic organisms, including purple bacteria, which absorb in the near infra-red (NIR), whose genera are the most abundant ones and contribute significantly to $\mathrm{CO}_{2}$ fixation and $\mathrm{O}_{2}$ evolution on the Earth..$^{95}$ The discovery of $\mathrm{Chl} d$ and $f$ in oxygenic photosynthetic organisms has implied that it might be introduced into algae or higher plants and allows them to utilize the $700-750 \mathrm{~nm}$ spectral regions, which is far from all known eukaryotic photosynthetic organisms to absorb ${ }^{96}$ and gives access to $19 \%$ additional photon flux. ${ }^{55}$ This possibility has been recently proposed in a number of published papers. ${ }^{94}$ For such a new or novel organisms, PAR cannot be of reasonable help, whereby it does not include FR or NIR.

\section{Conclusion}

The drawbacks of PAR stimulated us to propose an opinion on improving conventional PAR to provide a light measurement of functional wavelengths, the shortest and the longest wavelengths radiated from the Sun and artificial light sources and perceived by plants. We have tried to briefly discuss some problems arisen from conventional use of PAR in pieces of research focused or reported on light treatment effects on non-photo synthetic or photosynthetic parameters that are somehow a function of non-photosynthetic events. We have reviewed and relied on more recent papers to support our opinion. We are aware that there is a myriad of published papers reporting light in PAR while investigating non-photosynthetic or photosynthetic events. Apart from a brief glimpse at a few spectra contributions in PAR definition, we have attempted to shed light on invisible part of electromagnetic radiation to draw attention to the importance of taking into account the direct or indirect effects of non-PAR spectra on plant growth and development. An underlying assumption is that conventional PAR has served enough scientific studies, as previously lux had done, and we had better to update it to enlighten still little-known aspects of photosynthetic organisms. In conclusion, we suggest an improvement to conventional PAR using a SPF-based extended PAR (EPAR) including spectra from UV-B to IR (290-850nm). Therefore, a versatile EPAR will provide further raw and precise information to be considered in many fields of research, from in vitro to in situ, molecular to ecosystem scale, lower to higher plants.

\section{Acknowledgements}

None.

\section{Conflict of interest}

The author declares no conflict of interest.

\section{References}

1. Mc Cree KJ. Photo synthetically active radiation. In: Lange OL, et al, editors. Physiological Plant Ecology I. Germany: Springer; 1981. p. 41-55.

2. Sakshaug E, Bricaud A, Dandonneau Y, et al. Parameters of photosynthesis: Definitions, theory and interpretation of results. J Plankton Res. 1997;19(11):1637-1670.

3. Hartman PE, Biggley WH. Breakthrough of ultraviolet light from various brands of fluorescent lamps: Lethal effects on DNA repair-defective bacteria. Environ Mol Mutagen. 1996;27(4):306-313.
4. Deutch B, Rasmussen O. Growth chamber illumination and photo morphogenetic efficacy I. Physiological action of infrared radiation beyond 750nm. Physiol Plantarum. 1974;30(1):64-71.

5. Seibert M, Wetherbee PJ, Job DD. The effects of light intensity and spectral quality on growth and shoot initiation in tobacco callus. Plant Physiol. 1975;56(1):130-139.

6. Withrow AP, Withrow RB. Plant growth with artificial sources of radiant energy. Plant Physiol. 1947;22(4):494-513.

7. Bornman JF, Barnes PW, Robinson SA, et al. Solar ultraviolet radiation and ozone depletion-driven climate change:Effects on terrestrial ecosystems. Photochem Photobiol Sci. 2015;14(1):88-107.

8. Björn LO. Principles and nomenclature for the quantification of light. In: Björn LO editor. Photobiology: The science of light and life. 3rd ed. The Netherland; 2015. p. 41-49.

9. Salisbury FB. Summary of the international system of units (SI Units) In: Salisbury FB editors. Units, symbols, and terminology for plant physiology: A reference for presentation of research results in the plant sciences. USA: OUP; 1986. p. 3-20.

10. Abbas T, Balal RM, Shahid MA, et al. Silicon-induced alleviation of $\mathrm{NaCl}$ toxicity in okra (Abelmoschus esculentus) is associated with enhanced photosynthesis, osmoprotectants and antioxidant metabolism. Acta Physiologiae Plantarum. 2015;37:1-6.

11. de Freitas-Silva L, de Araújo TO, da Silva LC, et al. Arsenic accumulation in Brassicaceae seedlings and its effects on growth and plant anatomy. Ecotoxicol Environ Saf. 2016;124:1-9.

12. del Rosario Cappellari L, Santoro MV, Reinoso H, et al. Anatomical, morphological, and phytochemical effects of inoculation with plant growth-promoting Rhizobacteria on peppermint (Mentha piperita). $J$ Chemic Ecol. 2015;41(2):149-158.

13. Jiang Q, Wang F, Tan HW, et al. De novo transcriptome assembly, gene annotation, marker development, and miRNA potential target genes validation under abiotic stresses in Oenanthe javanica. Mol Genet Genomics. 2015;290(2):671-683.

14. Kaur R, Kapoor M. Plant regeneration through somatic embryogenesis in sugarcane. Sugar Tech. 2016;18(1):93-99.

15. Khan MA, Munive S, Bonierbale M. Early generation in vitro assay to identify potato populations and clones tolerant to heat. Plant Cell Tiss Org Cult. 2015;121(1):45-52.

16. Mayo S, Gutiérrez S, Malmierca MG, et al. Influence of Rhizoctonia solani and Trichoderma spp. in growth of bean (Phaseolus vulgaris L.) and in the induction of plant defense-related genes. Front Plant Sci. 2015;6:685.

17. Nitschke N, Wiesner K, Hilke I, et al. Increase of fast nutrient cycling in grassland microcosms through insect herbivory depends on plant functional composition and species diversity. Oikos. 2015;124(2):161173.

18. Tian L, Meng Q, Wang L, et al. Research on the effect of electrical signals on growth of Sansevieria under light-emitting diode (LED) lighting environment. PLOS ONE. 2015;10:e0131838.

19. Zhang Y, Tang S, Liu K, et al. The allelopathic effect of Potentilla acaulis on the changes of plant community in grassland, northern China. Ecol Res. 2015;30(1):41-47.

20. Crop Science Society; 2012.

21. Chen YR, Su YS, Tu SL. Distinct phytochrome actions in nonvascular plants revealed by targeted inactivation of phytobilin biosynthesis. Proc Natl Acad Sci USA. 2012;109(21):8310-8315. 
22. Ohashi-Kaneko K, Matsuda R, Goto E, et al. Growth of rice plants under red light with or without supplemental blue light. Soil Sci Plant Nutr. 2006;52(4):444-452.

23. Blasco M, Badenes ML, del Mar Naval M. Colchicine-induced polyploidy in loquat (Eriobotrya japonica (Thunb.) Lindl.). Plant Cell Tiss Org. 2015;120(2):453-461.

24. Zitterl-Eglseer K, Nell M, Lamien-Meda A, et al. Effects of root colonization by symbiotic arbuscular mycorrhizal fungi on the yield of pharmacologically active compounds in Angelica archangelica L. Acta Physiol Plantarum. 2015;37:1-21.

25. http://www.osram.com/media/resource/hires/333565/light-can-bewhite-en.pdf

26. http://assets.sylvania.com/assets/documents/faq0041-0800.83f1d8de3fe1-4d24-a209-d95f6cac74b9.pdf

27. http://download.p4c.philips.com/1fb/f/fp-927926284032/fp927926284032_pss_en_aa_001.pdf

28. Leiser AT, Leopold AC, Shelley AL. Evaluation of light sources for plant growth. Plant Physiol. 1960;35(3):392-395.

29. Warrington IJ, Mitchell KJ, Halligan G. Comparisons of plant growth under four different lamp combinations and various temperature and irradiance levels. Agr Meteorol. 1976;16:231-245.

30. Duke WB, Hagin RD, Hunt JF, et al. Metal halide lamps for supplemental lighting in greenhouses:Crop response and spectral distribution. Agron J. 1975;67(1):49-53.

31. Roberts GL, Tsujita MJ, Dansereau B. Supplemental light quality affects bud break, yield, and vase life of cut roses. Hort Sci. 1993;28(6):621622 .

32. Yorio NC, Mackowiak CL, Wheeler RM, et al. Vegetative growth of potato under high-pressure sodium, high-pressure sodium SON-Agro, and metal halide lamps. Hort Sci. 1995;30(2):374-376.

33. Björn LO. Generation and control of light. In: Björn LO editor. Photobiology: The science of life and light. Netherland: Springer; 2008. p. $51-67$.

34. Huang X, Ouyang X, Yang P, et al. Arabidopsis FHY3 and HY5 positively mediate induction of COP1 transcription in response to photomorphogenic UV-B light. Plant Cell. 2012;24(11):4590-4606.

35. Robson T, Klem K, Urban O, et al. Re-interpreting plant morphological responses to UV-B radiation. Plant cell environ. 2015;38(5):856-866.

36. Britz SJ, Sager JC. Photomorphogenesis and photoassimilation in soybean and sorghum grown under broad spectrum or blue-deficient light sources. Plant Physiol. 1990;94(2):448-454.

37. Li H, Tang C, Xu Z, et al. Effects of different light sources on the growth of non-heading Chinese cabbage (Brassica campestris L.). J Agricultural Sci. 2012;4(4):262-273.

38. Matsuda R, Ohashi-Kaneko K, Fujiwara K, et al. Effects of blue light deficiency on acclimation of light energy partitioning in PSII and $\mathrm{CO}_{2}$ assimilation capacity to high irradiance in spinach leaves. Plant cell Physiol. 2008;49(4):664-670.

39. Gautam P, Terfa MT, Olsen JE, et al. Red and blue light effects on morphology and flowering of Petunia $\times$ hybrid. Sci Hortic. 2015; 184:171-178.

40. Aasamaa K, Aphalo PJ. Effect of vegetational shade and its components on stomatal responses to red, blue and green light in two deciduous tree species with different shade tolerance. Environ Exp Bot. 2015;121:94101.
41. Massa GD, Kim HH, Wheeler RM, et al. Plant productivity in response to LED lighting. Hort Sci. 2008;43:1951-1956.

42. Goto E. Effects of light quality on growth of crop plants under artificial lighting. Environ Control Biol. 2003;41(2):121-132.

43. Kagami H, Kurata M, Matsuhira H, et al. Sugar beet (Beta vulgaris L.). In: Wang K editor. Agrobacterium Protocols. USA; 2015. p. 335-347.

44. Hoffmann AM, Noga G, Hunsche M. High blue light improves acclimation and photosynthetic recovery of pepper plants exposed to UV stress. Environ Exp Bot. 2015;109:254-263.

45. Nhut DT, Huy NP, Tai NT, et al. Light-emitting diodes and their potential in callus growth, plantlet development and saponin accumulation during somatic embryogenesis of Panax vietnamensis Ha et Grushv. Biotechnol Biotechnol Equip. 2015;29(2):299-308.

46. Zdarska M, Dobisová T, Gelová Z, et al. Illuminating light, cytokinin, and ethylene signalling crosstalk in plant development. $J$ Exp Botany. 2015;66(16):4913-4931.

47. Cerdán PD, Chory J. Regulation of flowering time by light quality. $\mathrm{Na}$ ture. 2003;423(6942):881-885.

48. Turnbull TL, Barlow AM, Adams MA. Photosynthetic benefits of ultraviolet-A to Pimelea ligustrina, a woody shrub of sub-alpine Australia. Oecologia. 2013;173(3):375-385.

49. Wang XY, Xu XM, Cui J. The importance of blue light for leaf area expansion, development of photosynthetic apparatus, and chloroplast ultrastructure of Cucumis sativus grown under weak light. Photosynthetica. 2015;53(2):213-222.

50. Bergstrand KJ, Schüssler HK. Growth, development and photosynthesis of some horticultural plants as affected by different supplementary lighting technologies. Europ J Hort Sci. 2013;78(3):119-125.

51. Sæbø A, Krekling T, Appelgren M. Light quality affects photosynthesis and leaf anatomy of birch plantlets in vitro. Plant Cell Tiss Org Cult. 1995;41(2):177-185.

52. Makino A, Mae T, Ohira K. Photosynthesis and ribulose 1,5bisphosphate carboxylase in rice leaves changes in photosynthesis and enzymes involved in carbon assimilation from leaf development through senescence. Plant Physiol. 1983;73(4):1002-1007.

53. Hudson GS, Evans JR, von Caemmerer S, et al. Reduction of ribulose-1, 5-bisphosphate carboxylase/oxygenase content by antisense RNA reduces photosynthesis in transgenic tobacco plants. Plant Physiol. 1992;98(1):294-302.

54. Opez-Juez E, Hughes MG. Effect of blue light and red light on the control pea leaves to increased fluence rates of chloroplast acclimation of light-grown pea leaves to increased fluence rates. Photochem Photobiol. 1995;61(1):106-111.

55. Evans JR. Improving photosynthesis. Plant Physiol. 2013;162:1780 1793.

56. Bais AF, McKenzie RL, Bernhard G, et al. Ozone depletion and climate change: Impacts on UV radiation. Photochem Photobiol Sci. 2015;14(1):19-52.

57. Kakani VG, Reddy KR, Zhao D, et al. Field crop responses to ultraviolet-B radiation: a review. Agr Forest Meteorol. 2003;120:191-218.

58. Ballaré CL, Caldwell MM, Flint SD, et al. Effects of solar ultraviolet radiation on terrestrial ecosystems. Patterns, mechanisms, and interactions with climate change. Photochem Photobio Sci. 2011;10(2):226-241.

59. Deckmyn G, Impens I. UV-B increases the harvest index of bean (Phaseolus vulgaris L.). Plant Cell Environ. 1995;18(12):1426-1433. 
60. Al-Oudat M, Baydoun SA, Mohammad A. Effects of enhanced UV-B on growth and yield of two Syrian crops wheat (Triticum durum var. Horani) and broad beans (Vicia faba) under field conditions. Environ Exp Bot. 1998;40:11-16.

61. Xu J, Gao K. Use of UV-A Energy for Photosynthesis in the Red Macroalga Gracilaria lemaneiformis. Photochem Photobiol. 2010;86(3):580-585.

62. Bernal M, Verdaguer D, Badosa J, et al. Effects of enhanced UV radiation and water availability on performance, biomass production and photoprotective mechanisms of Laurus nobilis seedlings. Environ Exp Bot. 2015;109:264-275.

63. Vandenbussche F, Tilbrook K, Fierro AC, et al. Photoreceptor-mediated bending towards UV-B in Arabidopsis. Mol Plant. 2014;7(6):10411052 .

64. Nair GB, Dhoble SJ. A perspective perception on the applications of light-emitting diodes. Luminescence. 2015;30(8):1167-1175.

65. Ma X, Wang Y, Liu M, et al. Effects of green and red lights on the growth and morphogenesis of potato (Solanum tuberosum L.) plantlets in vitro. Sci Hortic-Amsterdam. 2015;190:104-109.

66. Morales LO, Tegelberg R, Brosché M, et al. Effects of solar UV-A and $\mathrm{UV}-\mathrm{B}$ radiation on gene expression and phenolic accumulation in Betula pendula leaves. Tree Physiol. 2010;30(7):923-934.

67. Li Q, Kubota C. Effects of supplemental light quality on growth and phytochemicals of baby leaf lettuce. Environ Exp Bot. 2009;67(1):59 64.

68. Samuolienė G, Brazaitytė A, Urbonavičiūtė A, et al. The effect of red and blue light component on the growth and development of frigo strawberries. Zemdirbyste-Agriculture. 2010;97(2):99-104.

69. Brazaitytė A, Viršilè A, Jankauskienè J, et al. Effect of supplemental UV-A irradiation in solid-state lighting on the growth and phytochemical content of microgreens. Int Agrophys. 2015;29(1):13-22.

70. Feild TS, Lee DW, Holbrook NM. Why leaves turn red in autumn. The role of anthocyanins in senescing leaves of red-osier dogwood. Plant Physiol. 2001;127:566-574.

71. Ritz T, Damjanović A, Schulten K, et al. Efficient light harvesting through carotenoids. Photosynthesis Res. 2001;66(1-2):125-144.

72. Hogewoning SW, Wientjes E, Douwstra P, et al. Photosynthetic quantum yield dynamics: From photosystems to leaves. Plant Cell. 2012;24(5):1921-1935.

73. Li F, Li M, Zhan C, Wang S. A reliable and high-efficiency Agrobacterium tumefaciens-mediated transformation system of Pogonatherum paniceum embryogenic callus using GFP as a reporter gene. Plant Cell Tiss Org Cult. 2015;120(1):155-165.

74. Talukder P, Talapatra S, Ghoshal N, et al. Antioxidant activity and highperformance liquid chromatographic analysis of phenolic compounds during in vitro callus culture of Plantago ovata Forsk. and effect of exogenous additives on accumulation of phenolic compounds. $J \mathrm{Sci}$ Food Agric. 2016;96(1):232-244.

75. Hiei Y, Komari T. Agrobacterium-mediated transformation of rice using immature embryos or calli induced from mature seed. Nat Protoc. 2008;3(5):824-834

76. Kshirsagar PR, Chavan JJ, Umdale SD, et al. Highly efficient in vitro regeneration, establishment of callus and cell suspension cultures and RAPD analysis of regenerants of Swertia lawii Burkill. Biotech Rep. 2015;6:79-84.
77. Yamamoto S, Hayashi S, Furusaki S, et al. 5-Aminolevulinic acid promotes callus growth and paclitaxel production in light-grown Taxus cuspidata suspension cultures. Eng Life Sci. 2015;15(1):116-121.

78. Kim YG, Sharmin SA, Alam I, et al. Agrobacterium-mediated transformation of reed (Phragmites communis Trinius) using mature seed-derived calli. GCB Bioenergy. 2013;5(1):73-80.

79. Ros J, Tevini M. Interaction of UV-radiation and IAA during growth of seedlings and hypocotyl segments of sunflower. $J$ Plant Physiol. 1995;146(3):295-302.

80. Went FW. Competition among plants. Proc Natl Acad Sci USA. 1973;70(2):585-590.

81. Hohmann-Marriott MF, Blankenship RE. Evolution of photosynthesis Annu Rev Plant Biol. 2011;62:515-548.

82. Pettai H, Oja V, Freiberg A, et al. Photosynthetic activity of far-red light in green plants. Biochim Biophys Acta. 2005;708(3):311-321.

83. Thapper A, Mamedov F, Mokvist F, et al. Defining the far-red limit of photosystem II in spinach. Plant Cell. 2009;21(8):2391-2401.

84. Mokvist F, Mamedov F, Styring S. Defining the far-red limit of Photosystem I the primary charge separation is functional to $840 \mathrm{~nm} . J$ Biol Chem. 2014;289(35):24630-24639.

85. Schlodder E, Lendzian F, Meyer J, et al. Long-wavelength limit of photochemical energy conversion in photosystem I. J Am Chem Soc. 2014;136(10):3904-3918.

86. Miyashita H, Ikemoto H, Kurano N. Chlorophyll d as a major pigment. Nature. 1996;383:402.

87. Hu Q, Miyashita H, Iwasaki I, et al. A photosystem I reaction center driven by chlorophyll d in oxygenic photosynthesis. Proc Natl Acad Sci USA. 1998;95(22):13319-13323.

88. Tomo T, Okubo T, Akimoto S, et al. Identification of the special pair of photosystem II in a chlorophyll d-dominated cyanobacterium. Proc Natl Acad Sci USA. 2007;104(17):7283-7288.

89. Loughlin P, Lin Y, Chen M. Chlorophyll d and Acaryochloris marina: Current status. Photosynthesis Res. 2013;116(2-3):277-293.

90. Chen M, Schliep M, Willows RD, et al. A red-shifted chlorophyll. Science. 2010;329(5997):1318-1319.

91. Mohr R, Voß B, Schliep M, et al. A new chlorophyll d-containing cyanobacterium:Evidence for niche adaptation in the genus Acaryochloris. ISME J. 2010;4(11):1456-1469.

92. Airs RL, Temperton B, Sambles C, et al. Chlorophyll $\mathrm{f}$ and chlorophyll $\mathrm{d}$ are produced in the cyanobacterium Chlorogloeopsis fritschii when cultured under natural light and near-infrared radiation. FEBS Lett. 2014;588(20):3770-3777.

93. Gan F, Shen G, Bryant DA. Occurrence of far-red light photoacclimation (FaRLiP) in diverse cyanobacteria. Life. 2014;5(1):4-24.

94. Li Y, Chen M. Novel chlorophylls and new directions in photosynthesis research. Funct Plant Biol. 2015;42(6):493-501.

95. Garcia-Pichel F, Belnap J, Neuer S, et al. Estimates of global cyanobacterial biomass and its distribution. Algol Stud. 2003;109(1):213-227.

96. Chen M, Blankenship RE. Expanding the solar spectrum used by photosynthesis. Trends Plant Sci. 2011;16(18):427-431. 